\title{
A review and a conceptual framework of the key value drivers of mass customisation
}

\section{Raphael Damm* and Carmen de Pablos Heredero}

Universidad Rey Juan Carlos, Paseo Artilleros s/n. 28032 Vicálvaro, Madrid, Spain

E-mail: R.damm@alumnos.urjc.es

E-mail: Carmen.depablos@urjc.es

*Corresponding author

\section{Carlos Rodríguez-Monroy}

Universidad Politécnica de Madrid,

c/José Gutiérrez Abascal 2, 28006 Madrid, Spain

E-mail: Crmonroy@etsii.upm.es

\begin{abstract}
The aim of this paper is to conceptualise the key value drivers of mass customisation in order to provide a structured approach to explain the added value that customers attribute to mass customised products. We assume that the added value of mass customisation is ultimately reflected in an increased willingness to pay. Previous studies show diverse results concerning customers' willingness to pay for mass customised products. We contribute to the existing body of research by suggesting and discussing the influence of general product characteristics and factors of the mass customisation approach on the key value drivers of mass customisation. Furthermore, the development of a conceptual framework offers explanations for the dissimilarity in customers' willingness to pay and advances the knowledge about the value increment of mass customised products as perceived by customers.
\end{abstract}

Keywords: mass customisation; MC; value for the customer; success factors; willingness to pay; WTP; marketing; framework; key value drivers.

Reference to this paper should be made as follows: Damm, R., de Pablos Heredero, C. and Rodríguez-Monroy, C. (2013) 'A review and a conceptual framework of the key value drivers of mass customisation', Int. J. Technology Marketing, Vol. 8, No. 4, pp.411-430.

Biographical notes: Raphael Damm received his Doctor of Business Administration from the Rey Juan Carlos University in Madrid where he investigated the added value of mass customisation. Further, he is a Graduate Engineer from Technische Hochschule Mittelhessen (THM), Germany and holds a Master degree in Industrial Engineering from the Technical University Madrid (UPM). His research interests include knowledge management, customer integration and customer relationship management.

Carmen de Pablos Heredero is a Professor in the Business Administration Area at the Rey Juan Carlos University in Madrid, Spain from 1994. She is responsible for the $\mathrm{PhD}$ in Business Administration. She specialised in the impact of information technologies over organisational systems where she develops main research. She has chaired doctoral dissertations and projects on 
the impact of information and communication technologies in organisational performance. She has presented communications in different international venues and has published 78 articles in specialised journals and eight books. She has also worked as a Consultant in the area of IS Management at Prima Consulting.

Carlos Rodríguez-Monroy is a Professor of Corporate Strategy and Business Administration at Madrid Technical University (UPM). He coordinates doctoral programmes in collaboration with Latin American universities. $\mathrm{He}$ holds a degree in Industrial Engineering (1973) and a $\mathrm{PhD}$ in Industrial Organisation (1991) from UPM. He has coordinated two Erasmus-Mundus Master Programmes and is an active member of LACCEI (Latin American and Caribbean Consortium of Engineering Institutions).

\section{Introduction}

The concept of mass customisation (MC) has received increasing attention from academics and practitioners since it has been introduced by Davis (1987). Definitions of $\mathrm{MC}$ vary and have developed over time. For the purpose of this research we define MC as a customer centric strategy that enables customers to design or develop diverse products autonomously with the help of configurator systems. Generally, it is argued that mass customised products provide additional value to customers and that the value increment stems from an increase in the so-called 'preference fit', a better fit between customers' preferences and products' attributes, as well as from products' uniqueness, which customers attribute to self-designed objects (Franke and Schreier, 2008; Ulrich et al., 2003). However, recent research has shown that besides the increase in preference fit and products' uniqueness other factors affect customers' willingness to use $\mathrm{MC}$ as well (Franke et al., 2009; Kaplan et al., 2007).

To our knowledge, no comprehensive conceptualisation of customers' motives to engage in MC exists. In some studies selected key value drivers have been presented and their impact on customers' acceptance to use MC as well as customers' willingness to pay (WTP) has been investigated. Nevertheless, a comprehensive model that focuses on multiple factors in order to explain why customers prefer mass customised products over conventional ones does not exist. Therefore, the objective of this research is to conceptualise the key value drivers of MC mentioned in academic literature and relate them to the characteristics of products and the MC process. In order to do so, we discuss the key value drivers of MC as well as relevant factors of products and the MC process that determine products' adequacy for $\mathrm{MC}$ or influence the relevance of the key value drivers.

The underlying assumption that we make is that customers' WTP is influenced by the value provided by the MC approach. The added value that MC provides, in turn, is affected by product and MC process specific characteristics. Therefore, it is important to differentiate between the MC process and product specific factors and customers' perception of the key value drivers in order to determine the origin of the value added by MC. The composition of product and MC process factors that are addressed in MC 
approaches provides a central step in order to understand the gradual value increments of MC approaches.

In this article, we discuss key value drivers followed by crucial characteristics of products and the MC process. Selected research is reviewed in order to compile factors impacting customers' perception of the value of MC. Then a framework is proposed and relations between the incorporated factors are established. The organisation of the factors contributes to existing research by offering a framework that simultaneously considers various aspects. This offers the opportunity to further test not only which factors are important for customers' value perception but also to establish a hierarchy of the most influential factors.

Figure 1 Illustration of factors influencing customers' WTP for mass customised products

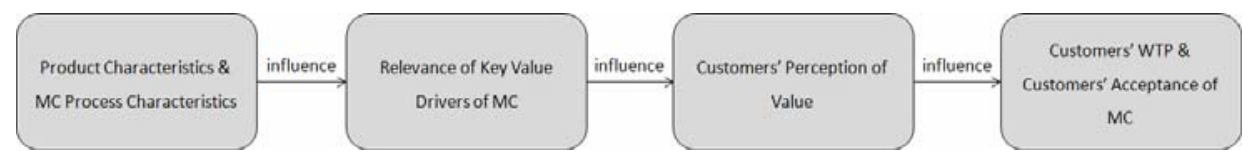

\section{Literature review}

We drew upon a number of selected empirical and conceptual research papers and integrated the findings to form a framework that explains the differences in customers' WTP. Relevant research was identified by searching scholarly journals in the Abi/Global Inform database. A number of search terms were used to narrow down articles dealing with MC and the underlying success factors. Complementary research mentioned in the reviewed articles was also consulted. Researchers have identified a number of product characteristics and, more recently, the MC process itself as an important value driving activity, which satisfies customers' hedonic needs. Various independent studies have found an increase in customers' WTP for mass customised products (e.g., Franke et al., 2009; Piller, 2004). However, the increase in the amount customers are willing to pay has been reported to be rather diverse.

For example, Schreier (2006) stated that customers' WTP increased by $207 \%$ for a self-designed cell phone cover, $113 \%$ for a self-designed T-shirt, and $106 \%$ for a self-designed scarf. Merle et al. (2008) found an average price premium of $28 \%$ for a pair of mass customised shoes, whereas Ives and Piccoli (2003, p.4) cited a study from 1997 in which it was "[...] found that $36 \%$ of consumers were willing to pay 12 to $15 \%$ more for custom apparel and footwear". Franke and Piller (2004, p.25) concluded their study by acknowledging that customers" "[...] WTP for a self-designed watch is almost twice as high as for the best selling standard model available on the market".

On the one hand, the variability in customers' WTP indicates that customers perceive the additional value provided by MC approaches in different ways. On the other hand, it has been suggested that using different measuring methods of customers' WTP results in different estimates (Merle et al., 2008). In the present research, rather than focusing on measurement methods of customers' WTP, we seek to investigate the origin of the added value in order to offer explanations for changes in customers' WTP. We concentrate on 
customers' perception of six key-value drivers and the impact of product and MC process characteristics on the key-value drivers.

The indirect impact of the MC experience on customers' WTP has been supported by the findings of Merle et al. (2008). Specifically, they differentiate between the mass customised product value and the experiential co-design value. The mass customised product value refers to utilitarian, uniqueness and self-expressiveness aspects, whereas the experiential co-design value is expressed in hedonic and creative achievements. Taken together, we distinguish the following drivers of perceived value:

1 an increase in preference fit (Franke et al., 2009)

2 a product's uniqueness (Fiore et al., 2004; Franke and Schreier, 2008; Lee and Chang, 2011)

3 the enjoyment perceived when customising a product (Fiore et al., 2004; Franke and Schreier, 2010)

4 the perception of pride to be the author of a product (Franke et al., 2010)

5 the feeling of psychological ownership (Franke et al., 2010).

Although feelings of pride of authorship and feelings of psychological ownership might appear to be alike they are conceptually different. Whereas feelings of pride stem from the perception of having made a contribution and having achieved something, psychological ownership refers rather to the incorporation of a product into the self so that it becomes an extension of one's personality and values. Furthermore, the perceived process effort during the customisation process is said to influence customers negatively (Dellaert and Stremersch, 2005). The proposed relationships between the key value drivers of MC and the characteristics of products and MC processes are illustrated in Figure 2. Following, the key value drivers of MC are discussed in detail.

Figure 2 Conceptual model of the relationships between product and MC process factors, the key value drivers of $\mathrm{mc}$, and customers' WTP

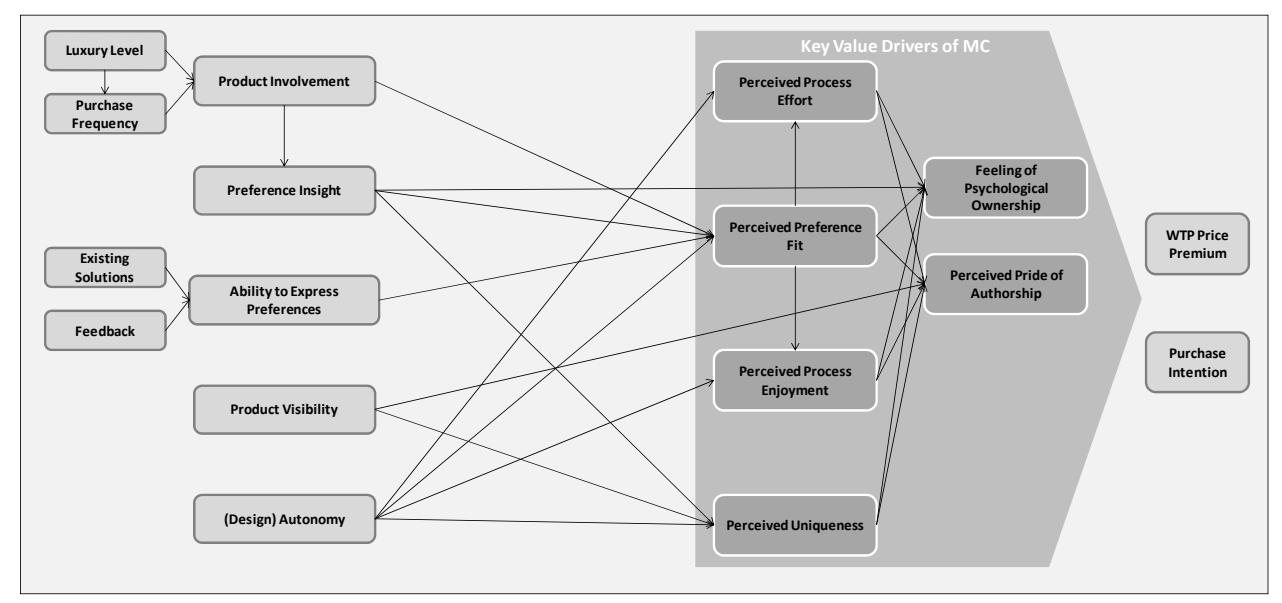




\subsection{The key value drivers of $M C$}

\subsubsection{Perceived preference fit}

Preference fit refers to the degree to which customers' preferences are satisfied. Franke and Schreier (2010) defined '[...] 'perceived preference fit' as the customer's subjective evaluation of the extent to which the product's features correspond to her preference system". This means that different product features will positively affect customers' perception of the preference fit only if they coincide with particular customer preferences. In the literature, preference fit is seen as the main value driver for customers engaging in MC (Franke and Schreier, 2010; Schreier, 2006) and the general view is that self-designing a product usually results in a higher preference fit, in terms of aesthetic and functional preferences. Assuming that customers' needs are heterogeneous, this provides superior value to customers.

The assumption that the perceived preference fit is the main value driver of MC implies that approaches to MC need to be designed in a way that customers are able to satisfy their preferences in order to derive additional value from MC. The ability to satisfy preferences is limited by the design freedom of the MC toolkit. Furthermore, the perceived preference fit might be affected by customers' ability to express their preferences, their level of product involvement, and their preference insight. The perceived preference fit itself might moderate the perception of the process enjoyment and effort (Franke and Schreier, 2010). When the perceived preference fit is high, customers' perception of the process enjoyment is amplified (Ibid.). Lastly, it might be argued that a high perceived preference fit is likely to lead customers to identify in a stronger way with the product. This could cause customers to develop feelings of psychological ownership and pride of authorship because designing a product that satisfies one's preferences to a high degree requires effort and dedication. The successful completion of the product design task should consequently evoke feelings of psychological ownership and pride.

\subsubsection{Perceived process enjoyment and effort}

Process effort refers to the extent of work associated with an activity in terms of time as well as mental and physical energy invested. Generally, it is argued that the effort should be as low as possible in order to facilitate the access for a great number of customers (Franke and Schreier, 2010). Conversely, it could also be argued that a high degree of process effort leads to investing the self into an object, which might lead to psychological ownership and results in a stronger dedication to the object. However, the effort involved in the process of self-designing a product has been portrayed as a disutility impacting customers' willingness to use MC toolkits and the likelihood of abandoning the customisation process without actually buying the product (Bendapudi and Leone, 2003; Dellaert and Stemersch, 2005; Huffman and Kahn, 1998). Contrary to this supposition Son et al. (2012) showed that 'mass confusion', which can be seen as a source of effort, increased the intentions to use $\mathrm{MC}$ related processes. Nevertheless, it is important to take into account that the process effort is determined by parameters such as the degree of design freedom. The degree of design freedom is a crucial factor since a great variety of options to choose from could overstrain customers. In an attempt to diminish process effort the degree of design freedom might be reduced. However, this could prevent 
customers from creating truly unique products. Consequently, the effects on other parameters should not be disregarded when minimising the process effort.

Bruner and Kumar (2005) found in their investigation of customer acceptance of using handheld internet devices that fun is a more powerful determinant of attitudes towards usage than perceived usefulness of the device. Fun, in turn, is achieved through ease of use. That is consistent with the findings of Thomke and von Hippel (2002) that toolkits for MC must be user-friendly in order to turn customers into innovators. In this context it is worthwhile to note that "[...] enjoyment is more than the absence of effort; although the perception of effort and enjoyment might be (negatively) correlated, they are conceptually independent" [Franke and Schreier, (2010), p.8]. Those findings suggest that the MC approach should be designed in such a manner that customers perceive the process not only as effortless but also as enjoyable.

Perceived enjoyment is described by Davis et al. (1992, p.1113) as "[...] the extent to which the activity of using the computer is perceived to be enjoyable in its own right, apart from any performance consequence that may be anticipated". Enjoyment has been considered a significant determinant in the adoption of a technology, comparable to the main constructs of the technology acceptance model (TAM), perceived usefulness and ease of use. Therefore, we argue that the perception of enjoyment in the process of MC constitutes a significant benefit to customers. In order to account for their relevance, Franke and Schreier (2010) recommend integrating both process effort and enjoyment in future models.

Figure 3 Research model proposed by Lee and Chang (2011)

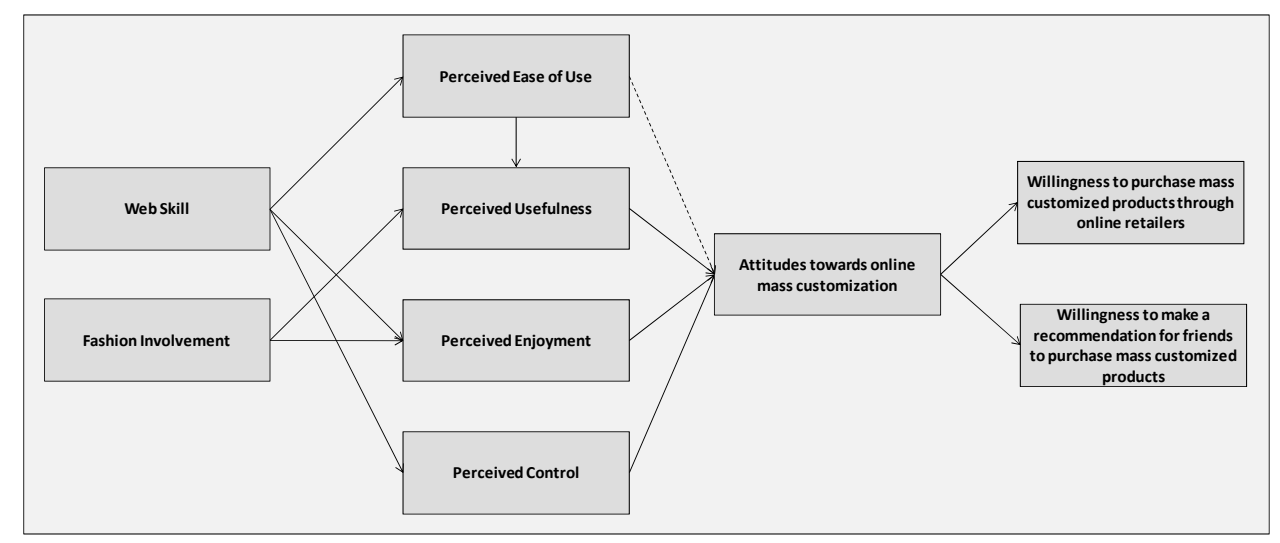

Furthermore, we argue that whether a process is perceived to be enjoyable is determined by the autonomy granted to customers and the perceived preference fit. A great degree of design autonomy enables customers to experience feelings of competence and creativity, two strong intrinsic drivers that allow the emergence of flow feelings (Csikszentmihalyi, 2002), which lead to enjoyment. A high preference fit leads to satisfaction and allows customers to enjoy their personalised product. The following figure illustrates an application of the extended TAM to MC by Lee and Chang (2011). We refer to what they call 'ease of use' as 'process effort' and use 'design autonomy' synonymously for the 
construct of 'perceived control'. Furthermore, it can be observed that the perception of ease of use, usefulness, enjoyment, and control affect customers' attitudes towards MC. In the model, we propose (Figure 2), we see customers' perceptions of the MC process and the resulting product influenced by a greater number of preceding factors.

\subsubsection{Perceived product uniqueness}

Product uniqueness refers to customers' perception about the rareness of a product. Unique products satisfy individuals' desires to be different and unique. "The core argument here is that the almost infinite variety of products offered by MC systems not only allows more effective adaptation to the customer's aesthetic and functional preferences, but also facilitates enhanced differentiation from other customers and their belongings by means of a truly unique product" [Franke and Schreier, (2008), p.3]. Enhancing individuality and being recognised as a unique individual with the help of a personalised product are the reasons why perceived uniqueness creates additional value for customers. Moreover, Franke and Schreier (2008) drew upon commodity theory arguing that perceived scarcity should augment the desirability of objects and that owning such objects facilitates differentiation from others.

Based on the following suppositions we see the perception of a product's uniqueness mainly influenced by the (design) autonomy of the MC approach, a product's visibility, and customers' preference insights as well as product involvement. An elevated degree of (design) autonomy enables customers to highly personalise their product and diminishes, at the same time, the chances that other customers will incorporate the same features in their product. Therefore, we see the degree of autonomy in the MC approach as a main driver of the perceived product uniqueness. Moreover, highly visible products that are used in public or are shared with others might be better suited for MC than products that are used in private and are not shared due to the fact that they can be observed by others. Possessions are part of a social communication system, in which customers compare their products with others and receive recognition (Richins, 1994). Consequently, the degree of product visibility determines whether customers can express their individuality through unique products or not. The degree of preference insight refers to customers' intimacy with a certain product category and its variations. Customers with a high degree of preference insight are likely to derive greater benefits from $\mathrm{MC}$ due to their knowledge about advantages and disadvantages of certain features (Franke et al., 2009).

Moreover, product involvement refers to the relevance of a certain product category and the value a customer attributes to that product category. Aligned with von Hippel (2005), we argue that customers with a high degree of product involvement are unlikely to compromise about 'their' product and propose that a high degree of product involvement is likely to indirectly influence one's need for a unique product.

The following figure illustrates the conceptual model proposed by Fiore et al. (2004). In this model the uniqueness of a product influences customers' willingness to use co-design directly. The precursors of the construct 'unique product' are three customer characteristics. For better generalisability we suggest using 'preference insight' instead of 'experience with appearance'. Similarly, we use 'process enjoyment' as an alternative for 'exciting experience'. 
Figure 4 Research model proposed by Fiore et al. (2004)

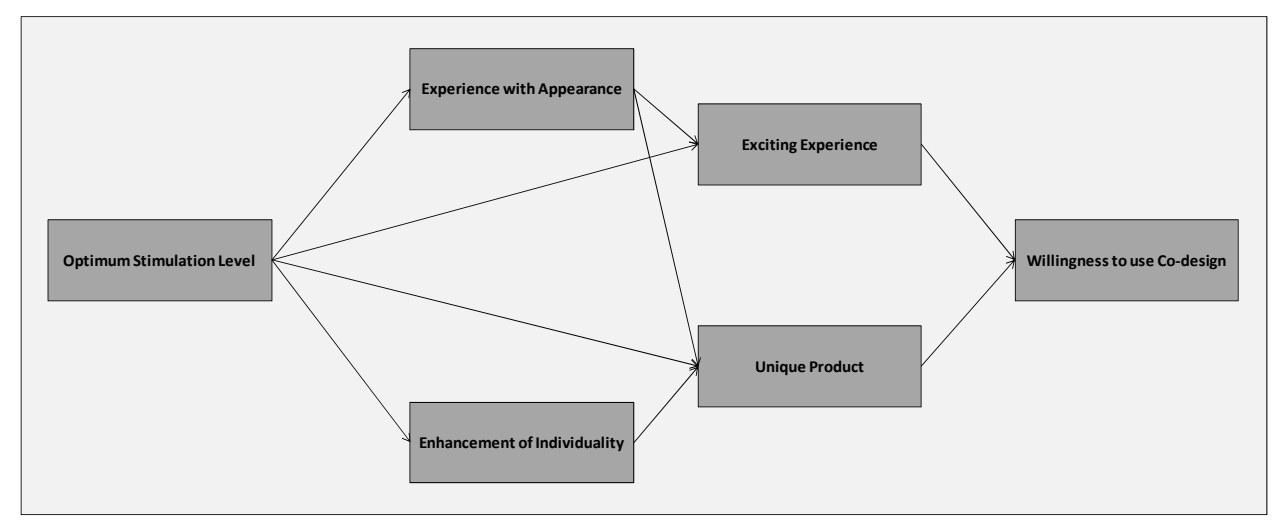

\subsubsection{Feelings of psychological ownership}

Ownership is generally attributed towards person-object relations. However, ownership can also be experienced towards non-physical articles such as ideas, words, artistic creations, and other people (Pierce et al., 2003). In order to clarify the idea of psychological ownership the fans of a sports team might serve as an analogy. Despite the fact that fans do not have legal relationships with teams, they have a certain connection to it, perceive it as theirs, and identify themselves with 'their' team. Furthermore, by supporting the team fans might feel in control of their environment. A customer's idea for a particular design or creation is the starting point in MC. Therefore, we argue that MC toolkits can promote the emergence of psychological ownership. The MC process leads to:

1 investing the self into the target-product

2 coming to intimately know the product

3 exercise control over the product.

Piecre et al. (2003) mentioned those three routes to psychological ownership and stressed that creating an object is probably the most powerful way to invest oneself into an object.

The existence of psychological ownership in the context of MC is of relevance since it is argued that ownership affects the value attributed towards an object. What is known as the endowment effect assumes that people assign a greater value to objects in their possession than to objects that they do not possess (Thaler, 1980). Kahneman et al. (1991) suggested that the main implication of the endowment effect is a certain loss aversion. This means that giving up a known situation is perceived less beneficial and riskier than staying in that situation. In the context of MC this effect becomes relevant in terms of psychological ownership. The fundamental supposition is that customers, who contribute in any kind of way to the development, production, or design of a product, might develop a feeling of ownership and consequently become more attracted to that product. The development of feelings of psychological ownership for a product, because customers invest time and effort to get to know, control and create it, is likely to manifest itself in a higher value attribution to that product due to the fact that customers do not want to give up their investment. 
In line with the endowment effect, Pierce et al. (2001, p.5) stated that "feelings of ownership are said to be pleasure producing per se" and that psychological owned objects become part of the extended self. Whereas legal ownership is not a requirement for psychological ownership and vice versa, the recognition of a personal meaning in the object's symbolic properties is a prerequisite in order to experience feelings of ownership. Efficacy and effectance, self-identity, and 'having a place' are said to be three human motives that lead to psychological ownership (Pierce et al., 2003). The term effectance refers to the ability to exert control over one's environment and relates possessions to the self, arguing that ownership enables individuals to affect their environment. Consumer goods, in particular, can serve as a way to manifest personal values, qualities, attitudes, education, social affiliation, and accomplishments. The personalisation of objects is related to security, identity, and individualism which stand for freedom and self-determination (Pierce et al., 2003). This implies that the attributes of an object influence the degree to which psychological ownership might develop. While personal differences influence the degree one attributes to possessions, Pierce et al. (2003) further argued that the degree to which the objects are controllable, subject to manipulation, or affecting the individual influence the perception of objects as a part of the extended self. Specifically, products that can be used, that are associated with emotions, or that have a special meaning are more likely to be perceived as a part of the extended self.

Moreover, Pierce et al. (2001, p.307) argued that in order to capture a user's interest and attention an object must be visible and attractive as well as it must "possess certain characteristics so that the motives for efficacy and effectance, self-identity, and/or need for a place could be fulfilled". In the same line, we propose that not only product characteristics favour the development of such motives but also characteristics of the MC process. The perceived process effort and enjoyment as well as the perception about the end result contribute to the development of psychological ownership. The three routes to psychological ownership (control, intimate knowledge, and investment of self) are all part of the MC process. Consequently, modifications of the MC process determining parameters might affect the routes to psychological ownership. For the design of MC toolkits this implies that restrictions, for example, in the design freedom might reduce the potential to develop psychological ownership.

\subsubsection{Perceived pride of authorship}

Drawing upon the theory of the extended self, the perception of feelings of pride from authorship can be explained by the transformation of psychic energy from the self into an object. Franke et al. (2010) argued that because of the investment of psychic energy in an object, in terms of effort, time and attention, the object might be regarded as a part of the self, which embodies a customer's accomplishment. Furthermore, Franke et al. (2010) analysed 'feeling of accomplishment' as a mediator and 'perceived contribution to the design' as a moderator of what they call the 'I designed it myself effect' and find clear evidence for the existence of a pride of authorship effect. This means that customers' perception about their contribution to the end result and customers' feelings of accomplishment influence the pride of authorship effect positively.

Franke et al. (2010, p.137) argued that "feelings of accomplishment arising from the process of self-designing largely impact the subjective value of the product". Similarly, Brabham $(2008$, p.82) resumed findings from a number of other researchers that 
recognition by others and especially "the pursuit of the problem and the satisfaction in finding a better solution to the problem" are important non-financial payments for innovators. Those findings provide evidence for the assumption that the motivation of customers to engage in MC is not only based on product and MC process factors but also on social factors such as the need for recognition, individuality, or pride of authorship. Whereas a product's uniqueness allows customers to display their individuality, the creation of a product (design) evokes feelings of pride that are founded in the perception of having made a contribution and having achieved something.

Moreover, Franke et al. (2010) found empirical evidence for the 'I designed it myself effect' and mention the perceived contribution to the MC process as a moderator. They state that it is unclear to which extent the feeling of having made a contribution is beneficial and suggest that beyond a certain maximum, additional contributions do not increase the value derived from MC activities. We argue that the main driver of perceived pride of authorship is the degree of (design) freedom of MC toolkits. It appears plausible that a high degree of design freedom enables customers to feel to have made a contribution, whereas a small degree of autonomy prevents the emergence of such feelings.

According to the self-determination theory the need for competence is said to be one of the psychological needs that motivates individuals to act in a way to achieve psychological health and well-being (c.f., Ryan and Deci, 2000). Franke et al. (2010) argued that the feeling of accomplishment contributes to feelings of competence, which are deeply embedded in human nature. This implies that it is important to support customers throughout the MC process, so that they can achieve a satisfactory result. Intrinsic rewards that induce feelings of competence are mentioned by Lakhani and von Hippel (2003) to be relevant for participants in Open Source software as well. Reichwald et al. (2004) also emphasise that the right balance of a task difficulty, between being challenging and doable, is important and that immediate feedback provides customers with a feeling of competence. If the right difficulty level is achieved customers are stimulated by the task they carry out and are motivated intrinsically.

The need for competence is central to the theory of intrinsic motivation and directly linked to feelings of interest and enjoyment (Lakhani and Wolf, 2003). Intrinsic motivations are said to emphasise inherent satisfactions such as altruism, fun, reciprocity, intellectual stimulations, and a sense of obligation to contribute (Ibid.). Therefore, feelings of accomplishment may only emerge when a certain level of autonomy is given and when the MC process results in a satisfactory outcome. In the same way, Franke et al. (2010) suggested immediate (positive) feedback as an additional stimulus in order to increase the feelings of accomplishment and being 'the cause' of the MC process along with a high degree of design autonomy and control over the $\mathrm{MC}$ process.

\subsection{Relevant factors of the mass customised product and the MC process}

Past studies have analysed success factors of MC activities mainly in an isolated way. More precisely, the effects of, for example, perceived contribution to the $\mathrm{MC}$ process, feelings of accomplishment, or process effort and enjoyment have been investigated, but no comprehensive framework has been established that would account for product characteristics and factors of the MC process at the same time. Fiore et al. (2004) suggested in their research on fashion products that the uniqueness of the product should be the primary marketing feature due to their findings that 'creating a unique product' has 
a stronger effect on customers' willingness to use MC than 'trying co-design as an exciting experience'. However, even within product categories differences between product characteristics influence the relevance of the success factors of MC making the generalisation of success factors difficult.

It seems reasonable to argue that the degree of importance customers attribute to sports shoes, T-shirts, or scarves varies. Therefore, it is likely that different value drivers underlie the successful employment of MC configurator systems for sports shoes, T-shirts, or scarves, even though all are fashion products. Consequently, in the design of MC configurator systems specific aspects of the underlying product, especially product immanent factors, should be taken into account in order to highlight corresponding value drivers. Given the multiplicity of factors impacting consumers' motivations to use MC, it is crucial to not only analyse the main but also the moderating and mediating effects. For example, the degree of preference insight might moderate the benefits customers derive from MC due to the fact that customers with a low degree of preference insight might not be able to evaluate whether a product fits their preferences or not. Franke et al. (2009) found that the effects of preference insight, the ability to express preferences, and product involvement on the benefit customers derive from customised products are moderated by the product category. The dissimilarity in the WTP for personalised scarves, T-shirts, or cell-phone covers, as mentioned above, illustrates that customers evaluate MC approaches differently. We suggest that the reasons for the dissimilarity can be found in the characteristics of the product, the MC process, and the customer. In order to offer an explanation for the differences in the value attribution we propose, in the following section, a number of factors that have the potential to significantly alter the relevance of the key value drivers of MC.

\subsubsection{Ability to express preferences, integration of existing solutions and feedback}

The main underlying value driver of $M C$, the perceived preference fit, is directly influenced by the ability of individuals to express their preferences. If individuals are unable to express their preferences, because they do not know them or because they cannot articulate them, MC is unlikely to generate value for them. MC toolkits offer customers the opportunity to express their preferences in a limited way and customer might not be fully aware of their preferences. Hence, the process outcome might not be a true representation of customers' preferences but rather a random choice (Franke et al., 2009). This would reduce the value customers derive from engaging in MC.

Based on Franke et al. (2008), we argue that supplementary information is helpful for problem solving in MC. Therefore, we suggest that the availability of feedback and the access to existing solutions (e.g., design drafts) positively affect customers' ability to express their preferences. External inspiration is likely to serve customers as a starting point on which they can build. Especially, users of MC approaches with little (design) experience and a low degree of preference insight are likely to benefit from suggestions and should consequently perceive the MC process as less challenging. Franke et al. (2008) showed empirically that the availability of existing design solutions from other customers, as an inspiration in the phase of developing an initial idea, positively influences a more systematic problem-solving approach. They also demonstrated that peer feedback influences the evaluation of preliminary design solutions. Therefore, we argue that the availability of existing solutions and feedback eventually lead to an 
improved ability to express preferences, which is likely to result in a superior process outcome.

Figure 5 shows an approach taken by Franke et al. (2009). They suggested that the three constructs 'preference insight', 'ability to express preferences', and 'product involvement' impact the benefits customers derive from $\mathrm{MC}$ and that the benefits further affect the price premium customers are willing to pay over conventional products. Customers' ability to express preferences might vary for a number of reasons; however, the availability of design ideas from others and the provision of feedback should augment customers' ability to express preferences.

Figure 5 Research model proposed by Franke et al. (2009)

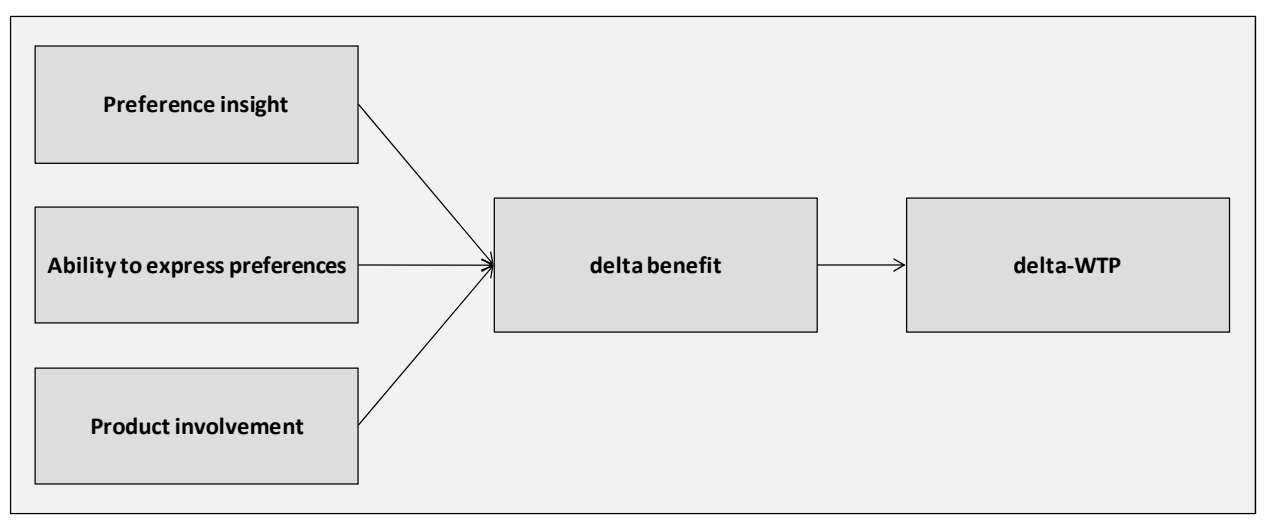

\subsubsection{Luxury level, purchase frequency, and product involvement}

Based on Zaichkowsky (1985), Franke et al. (2009, p.10) stated that "product involvement generally refers to the relevance of a specific product (category) as perceived by a customer on the basis of her individual needs, preferences and interests". Product involvement has been used as a moderating or explanatory variable and considered a central framework, which is crucial for the understanding of consumer decision-making behaviour and associated communications (Bian and Moutinho, 2011). We argue that the relevance of a product, in turn, is influenced by its luxury level and its purchase frequency. Furthermore, purchase frequency is influenced by a product's luxury level.

The relevance of a product defines the importance customers attribute to the object. A high degree of product involvement, therefore, implies that customers attribute a high value to the product. Moreover, research has shown that a product's personal relevance influences consumers' motivation to process information about it (Bian and Moutinho, 2011). Luxury products, that "tend to be more distinctive, higher priced, and unique" [Broekhuizen and Alsem, (2002), p.320] are less frequently purchased and consequently higher valued. Furthermore, luxury products do not fulfil basic needs but rather satisfy hedonic desires and might be bought in order to affirm one's social position. Moreover, psychological benefits such as social recognition and enhanced self-esteem enable luxury brands to be distinguished from others and are consequently perceived more unique 
(De Barnier et al., 2012). Therefore, we argue that the luxury level of products positively predicts a product's appropriateness for MC.

Lastly, purchase frequency is likely to impact the value customers derive from MC. Frequency is, in conjunction with recency, a fundamental measure in the evaluation of direct marketing promotions. We propose that products with a long lifetime, thus a low purchase frequency, are better suited for MC. Because MC is costly for customers, in terms of time and energy invested, they benefit longer from their investment and amortise their efforts throughout a longer period of time with long living products. This is contrary to Broekhuizen and Alsem (2002) who hypothesised that a high purchase frequency will positively affect the success of MC.

\subsubsection{Product visibility}

We define product visibility as the degree to which the results of a MC activity is visible and communicable to others (Moore and Benbasat, 1991). Ulrich et al. (2003) used the term 'sign' for the concept that refers to the capacity to express identity or status. Woodall (2003) defines 'single-stimulus value' as 'value for the customer' that stems from the relationship between an individual and a product only and 'dual-stimulus value' as 'value for the customer' that needs a secondary stimulus such as a social or commercial context. For example, products such as furniture are less visible than shoes due to the fact that they are not used in public. Similarly, some products such as cars are intended to be shared, whereas other products such as clothes are meant to be used by a single individual. Similar to Da Silveira et al. (2001) and Broekhuizen and Alsem (2002) we suggest that a product's degree of visibility influences the relevance of the key value drivers of MC due to the fact that others have an influence on one's behaviour. Franke and Schreier (2008, p.18) highlighted that for some product categories "the possibility of demonstrating individuality with the self-designed product is limited". This implies that products that are not used in public, and therefore are not visible to others, do not have the same potential to communicate the product attributes.

Moreau and Herd (2010) assert that displaying publicly one's abilities does not only serve as a means for repairing or enhancing self-regard but also provides the opportunity to achieve recognition, which leads to improving one's self-evaluation. Therefore, it seems reasonable to argue that differentiating between products that provide single-stimulus or dual-stimulus value is important in order to account for the potential to receive recognition. Furthermore, taking into account the communicative power of possessions, the feelings of competence a customer might perceive from using a $\mathrm{MC}$ configurator system is likely to be different for single-stimulus and dual-stimulus value providing products.

Based on the aforementioned we suggest that a product's degree of visibility considerably affects the value users derive from MC. Products that are used in a social context provide individuals with the opportunity to display their abilities. This gives way to feelings of pride of authorship due to recognition by others. Therefore, we argue that the level of visibility should be taken into account in the design of MC toolkits. If a product generates value for the customer without a secondary stimulus, consumers might be motivated by more personal values such as an enjoyable experience. Conversely, highly visible products might require a higher degree of autonomy of the $\mathrm{MC}$ approach so that customers can receive recognition for having created a truly unique product. 


\subsubsection{Design autonomy}

The degree of design autonomy of a MC approach is an important factor in order to enable customers to adapt products according to their preferences. The degree of design autonomy can be determined by the number of attributes subject to manipulation and available options per attribute. A high degree of design autonomy allows customers to highly personalise products and might serve as a key motivator to use MC. In a similar way, Moreau and Herd (2010) stated that customers who engage in creative tasks are motivated, to some extent, by a sense of autonomy.

From a customer's perspective, the optimal level of autonomy is given when the necessary options that satisfy customers' needs are available without overstraining them. This results not only in a higher perceived preference fit and a higher perception of uniqueness but also in a higher perceived process enjoyment and a lower perceived process effort. From a firm's point of view some restrictions to the MC process have to be made in order to secure that the production process works with a similar efficiency as in mass production and that information overload of customers is avoided. Taking this into account the right degree of design freedom is crucial as it influences the creativity customers perceive during the MC activity and therefore the feeling of competence they develop.

Establishing a degree of autonomy can be seen as a trade-off between reducing process effort and providing enough options that permit the creation of unique products that satisfy customers' needs. Although design effort has been said to have negative effects on the value customers derive from MC and even though it has been suggested that it should be as low as possible, we argue that process effort per se does not have a negative influence. Psychological ownership develops through investing the self into an object, getting to intimately know, and controlling it. Therefore, customers need to immerse themselves in the MC process to foster feelings of psychological ownership. Supposing that customers' perception about their contribution to the mass customised product affects their feeling of pride of authorship implies that the degree of autonomy is a crucial parameter of the MC process. A high degree of autonomy will rather have a positive effect on the perceived pride of authorship and the feeling of psychological ownership than a negative effect on the motivation to use $\mathrm{MC}$ as long as the $\mathrm{MC}$ process is enjoyable and well structured. Franke et al. (2010) provided empirical evidence that high design autonomy, measured as the perceived contribution, generates a higher WTP. Through a high degree of autonomy customers have the feeling to be in charge of what they do and consequently develop a feeling of responsibility. We suggest that this leads to greater intimacy with the product and further satisfies feelings of competence and evokes a need for recognition.

\subsubsection{Preference insight}

When product involvement or the relevance of a product is low, customers are likely to be unaware of their exact preferences (Simonson, 2005; Kramer, 2007). However, in order to achieve a high preference fit customers need to be aware of their preferences. In the same vein, Bharadwaj et al. (2009) drew upon the findings of earlier research and asserted that customers without insight into their preferences might not benefit from the matching process that $\mathrm{MC}$ provides. 
Franke et al. (2009) stated that the multitude of options in MC approaches is likely to deliver a random solution rather than an exact copy of a customer's ideal product. Consequently, a high degree of preference insight should positively influence the perception of the preference fit and the development of feelings of psychological ownership. Therefore, the insights about one's preferences should be augmented by exploring the target object, by using or creating it, or by learning from others. Furthermore, Franke et al. (2009) analysed the influence of customers' preference insight and their ability to express those preferences on the perceived preference fit. They showed empirically that the benefits derived from customisation depend on both factors as well as the product involvement. This intimates that MC approaches should be designed in a way that users can augment their preference insights, possibly through learning mechanisms, feedback, interaction with others, and exposure to solutions created by peers.

\section{Summary}

Based on the discussion provided above, we propose that an increased WTP stems from the additional value mass customised products provide. The additional value can be explained by an increase in preference fit, process enjoyment, a product's uniqueness, feelings of psychological ownership, and a pride of authorship effect. Furthermore, we suggest that the magnitude of those key value drivers is influenced jointly by factors of the product and the $\mathrm{MC}$ process. Considering the influence of the factors of the product and the MC process is crucial because a varying WTP indicates that not all products are equally suited for MC in the same way and not all MC approaches deliver identical value for customers.

In order to determine and maximise the relevance of the key value drivers, a product's use situation should be taken into account. A product's visibility, purchase frequency, and luxury level are helpful when deciding which key value drivers to focus on. In the design of MC approaches the underlying product characteristics should be taken into account in order to address suitable key value drivers. For example, highly visible products might be more adequate to express one's uniqueness due to the fact that they are observable by others and therefore offer the opportunity to receive recognition. MC approaches for products with a low degree of visibility, on the other hand, might deliver more value to customers and be more successful addressing feelings of pride or enjoyment.

Given the multitude of product categories addressed by MC approaches, a detailed discussion of the individual product characteristics would go beyond the scope of this research. Products that can be personalised through $\mathrm{MC}$ toolkits include, for example, apparel, automobiles, electronics, food, printed products and sports equipment. However, automobiles, for example, differ substantially from cereal bars in their purchase frequency, luxury level, visibility as well as their scope of design. A cereal bar is usually consumed without the need of a secondary or social stimulus and does not possess the relevance or the visibility of an automobile. Therefore, we assume that the relevance of the key value drivers for cereal bars differs substantially from the relevance of the key value drivers for automobiles. Consequently, we propose a categorisation of the fundamental product characteristics in order to approach the determination of products' key value drivers in a structured way. 
In general, we suggest that product involvement is mainly influenced by a product's luxury level and its purchase frequency. Products with a high luxury level are usually high priced and consequently purchased rather infrequently. Furthermore, scarce goods often possess a special value causing customers to attribute a special meaning to luxury goods. A high degree of purchase frequency implies a certain necessity for the product in question and an ability to afford it. The affordability implies a rather ordinary meaning and the necessity addresses the utilitarian value of a product. Based on the assumption that customers with a high degree of product involvement are unlikely to compromise about 'their' product, we suggest that the degree of product involvement mainly impacts the relevance of the perceived preference fit.

Furthermore, we suggest that customers' degree of preference insight is also influenced by the product involvement because an interest for a certain product implies that customers have, at least, some knowledge about it. Preference insight, in turn, positively affects the perception of the preference fit, the product's uniqueness and the feelings of psychological ownership. As stated earlier, psychological ownership develops from investing the self into an object and coming to intimately know it. In order to gain insights on one's preferences a product needs to be examined. Therefore, it can be argued that a high degree of preference insight implies the development of feeling of psychological ownership. In addition, we argue that the degree of preference insight should affect the perception of the product uniqueness because customers with a high degree of preference insight can determine the product's uniqueness more realistically. Lastly, a high degree of preference insight should positively influence customers' perception of the preference fit due to the fact that a high degree of preference insight implies a certain experience with the product which should prevent customers from making false choices such as bad combinations.

Concerning one's ability to express preferences, which can be advanced through the provision of feedback or design drafts, we suppose that it directly influences customers' perceived preference fit since products' attributes need to be specified in order to coincide with customers' preferences. Furthermore, the product visibility determines the degree to which customers will develop feelings of pride of authorship and have recognised the uniqueness of their self-designed product. Although customers can perceive pride of authorship and a product's uniqueness by themselves, we argue that recognition from others intensifies those feelings. The level of design freedom affects the perceived preference fit, product uniqueness, process effort and enjoyment since it enables customers to implement their ideas. If conditions do not permit customers to carry out their ideas those factors are unlikely to provide additional value.

\section{Discussion}

Throughout this article we have composed the key value drivers of MC and suggested a number of relevant product and MC process factors. Given the diversity of MC approaches offering the configuration of products such as automobiles, T-shirts, shoes, suits, cereals, chocolate, or bicycles it seems insufficient to argue that an increase in the perceived preference fit and a product's uniqueness are the only underlying value drivers of MC. Furthermore, different product categories and even different products within a product category address a number of diverse aspects. While some products are bought for their utilitarian value, other products provide customers with a hedonic, uniqueness, 
or self-expressiveness value. However, the perception of value is subjective and contingent. Therefore, we argue that the underlying factors of the product and MC process as well as the key value drivers should be taken into account in designing the $\mathrm{MC}$ approach.

The success of MC approaches ultimately depends on the acceptance by customers. In the light of the fact that Levi Strauss, Mattel, and other firms have discontinued their engagement in MC, it seems reasonable to investigate the factors that determine whether the pursuit of $\mathrm{MC}$ will be successful or not and under which circumstances it makes (economic) sense to offer MC. After all, the implementation of MC implies additional costs. Amongst others, production processes need to be modified and MC configurators have to be set up. Success, in financial terms, will only be reached if customers demand the personalisation of products and are willing to pay a price premium that covers the additional costs.

The conceptualisation of the key value drivers of $\mathrm{MC}$ provides a further step in order to better understand the value increment of mass customised products. We have proposed that the added value is ultimately reflected in an increased WTP. However, we suggest that customers could also be willing to make non-financial sacrifices for the additional value they receive from MC. As a matter of fact, customers invest time and energy and familiarise themselves with supplier specific processes. This demonstrates customers' willingness to make (non-financial) sacrifices. In the same way, customers could be willing to make referrals or provide additional information as a trade-off for the adoption of their product.

Lastly, we note the theoretical nature of this research and propose the analysis of different MC approaches taking the proposed factors of the product and MC process into account. In this way, it could be validated whether products with, for example, a high luxury level, a high visibility, or a low purchase frequency are more adequate for $\mathrm{MC}$ and whether those factors influence customers' WTP. Similarly, it would be of interest to examine whether customers who use MC approaches with a high degree of design freedom are willing to pay significantly more than customers' of comparable MC approaches with a low degree of design freedom. According to the relations proposed in the conceptual model we suggest the following example propositions for empirical testing:

1 A high degree of visibility positively influences customers'

a perception of the product uniqueness

b feelings of pride of authorship.

2 A high degree of preference insight positively affects customers' perception of the:

a preference fit

$\mathrm{b}$ product uniqueness

c feelings of psychological ownership.

3 A high degree of design autonomy affects customers' perception of the:

a preference fit

b process enjoyment

c product uniqueness positively and affects customers' perception of the

d process effort negatively. 
Moreover, the empirical validation of the effects of one's ability to express preferences and preference insight on the key value drivers of MC would be helpful in order to decide whether to incorporate learning mechanisms, feedback, or design drafts in order to support customers. Furthermore, the empirical validation of the impact of the key value drivers on customers' WTP would be helpful in order to decide on which factors to focus the MC approach of a certain product category. This would allow designing MC approaches more effectively and targeting customers' needs more precisely.

\section{References}

Bendapudi, N. and Leone, R.P. (2003) 'Psychological implications of customer participation in co-production', Journal of Marketing, Vol. 67, No. 1, pp.14-28.

Bharadwaj, N., Walker Naylor, R. and ter Hofstede, F. (2009) 'Consumer response to and choice of customized versus standardized systems', International Journal of Research in Marketing, Vol. 26, No. 3, pp.216-227.

Bian, X. and Moutinho, L. (2011) 'The role of brand image, product involvement, and knowledge in explaining consumer purchase behavior of counterfeits: direct and indirect effects', European Journal of Marketing, Vol. 45, Nos. 1/2, pp.191-216.

Brabham, C.D. (2008) 'Crowdsourcing as a model for problem solving: an introduction and cases', Convergence: The International Journal of Research into New Media Technologies, Vol. 14, No. 1, pp.75-90.

Broekhuizen, T.L.J. and Alsem, K.J. (2002) 'Success factors for mass customization: a conceptual model', Journal of Market-Focused Management, Vol. 5, No. 4, pp.309-330.

Bruner, G.C. and Kumar, A. (2005) 'Explaining consumer acceptance of handheld Internet devices', Journal of Business Research, Vol. 58, No. 5, pp.553-558.

Csikszentmihalyi, M. (2002) Creativity: Flow and the Psychology of Discovery and Invention, Harper Perennial, New York.

Da Silveira, G., Borenstein, D. and Fogliatto, F.S. (2001) 'Mass customization: literature review and research directions', International Journal of Production Economics, Vol. 72, No. 1, pp.1-13.

Davis, F.D., Bagozzi, R.P. and Warshaw, P.R. (1992) 'Extrinsic and intrinsic motivation to use computers in the workplace', Journal of Applied Social Psychology, Vol. 22, No. 14, pp.1111-1132.

Davis, S.M. (1987) Future Perfect, Addison-Wesley, Reading, Mass.

De Barnier, V., Falcy, S. and Valette-Florence, P. (2012) 'Do consumers perceive three levels of luxury? A comparison of accessible, intermediate and inaccessible luxury brands', Journal of Brand Management, Vol. 19, No. 7, pp.623-636.

Dellaert, B.G. and Stremersch, S. (2005) 'Marketing mass-customized products: striking a balance between utility and complexity', Journal of Marketing Research, Vol. 42, No. 2, pp.219-227.

Fiore, A.M., Lee, S.E. and Kunz, G. (2004) 'Individual differences, motivations, and willingness to use a mass customization option for fashion products', European Journal of Marketing, Vol. 38, No. 7, pp.835-849.

Franke, N. and Piller, F. (2004) 'Value creation by toolkits for user innovation and design: the case of the watch market', Journal of Product Innovation Management, Vol. 21, No. 6, pp.401-415.

Franke, N. and Schreier, M. (2008) 'Product uniqueness as a driver of customer utility in mass customization', Marketing Letters, Vol. 19, No. 2, pp.93-107.

Franke, N. and Schreier, M. (2010) 'Why customers value mass-customized products: the importance of process effort and enjoyment', Journal of Product Innovation Management, Vol. 27, No. 7, pp.1020-1031. 
Franke, N., Keinz, P. and Schreier, M. (2008) 'Complementing mass customization toolkits with user communities: how peer input improves customer self-design', Journal of Product Innovation Management, Vol. 25, No. 6, pp.546-559.

Franke, N., Keinz, P. and Steger, C. (2009) 'Testing the value of customization: when do customers really prefer products tailored to their preferences?', Journal of Marketing, Vol. 73, No. 5, pp.103-121.

Franke, N., Schreier, M. and Kaiser, U. (2010) 'The 'I designed it myself' effect in mass customization', Management Science, Vol. 56, No. 1, pp.125-140.

Huffman, C. and Kahn, B.E. (1998) 'Variety for sale: mass customization or mass confusion', Journal of Retailing, Vol. 74, No. 4, pp.491-513.

Ives, B. and Piccoli, G. (2003) 'Custom made apparel and individualized service at Lands' End', Communications of the Association for Information Systems, Vol. 11, No. 3, pp.1-27.

Kahnemann, D., Knetsch, J.L. and Thaler, R.H. (1991) 'Anomalies: the endowment effect, loss aversion, and status quo bias', The Journal of Economic Perspectives, Vol. 5, No. 1, pp.192-206.

Kaplan, A.M., Schoder, D. and Haenlein, M. (2007) 'Factors influencing the adoption of mass customization: the impact of base category consumption frequency and need satisfaction', Journal of Product Innovation Management, Vol. 24, No. 2, pp.101-116.

Kramer, T. (2007) 'The effect of measurement task transparency on preference construction and evaluations of personalized recommendations', Journal of Marketing Research, Vol. 44, No. 2, pp.224-233.

Lakhani, K.R. and von Hippel, E. (2003) 'How open source software works: 'free' user-to-user assistance', Research Policy, Vol. 32, No. 6, pp.923-943.

Lakhani, K.R. and Wolf, R.G. (2003) Why Hackers Do What They Do: Understanding Motivation and Effort in Free/Open Source Software Projects, MIT Sloan Working paper No. 4425-03.

Lee, H-H. and Chang, E. (2011) 'Consumer attitudes toward online mass customization: an application of extended technology acceptance model', Journal of Computer-Mediated Communication, Vol. 16, No. 2, pp.171-200.

Merle, A., Chandon, J-L. and Roux, E. (2008) 'Understanding the perceived value of mass customization: the distinction between product value and experiential value of co-design', Recherche et Applications en Marketing (English Edition), Vol. 23, No. 3, pp.27-50.

Moore, G.C. and Benbasat, I. (1991) 'Development of an instrument to measure the perceptions of adopting an information technology innovation', Information Systems Research, Vol. 2, No. 3 , pp.192-222.

Moreau, C.P. and Herd, K.B. (2010) 'To each his own? How comparisons with others influence consumers' evaluations of their self-designed products', Journal of Consumer Research, Vol. 36, No. 5, pp.806-819.

Pierce, J.L, Kostova, T. and Dirks, K.T. (2003) 'The state of psychological ownership: integrating and extending a century of research', Review of General Psychology, Vol. 7, No. 1, pp.84-107.

Pierce, J.L., Kostova, T. and Dirks, D.T. (2001) 'Toward a theory of psychological ownership in organizations', The Academy of Management Review, Vol. 26, No. 2, pp.298-310.

Piller, F. (2004) 'Mass customization: reflections on the state of the concept', The International Journal of Flexible Manufacturing Systems, Vol. 16, No. 4, pp.313-334.

Reichwald, R., Ihl, C. and Seifert, S. (2004) Kundenbeteiligung an unternehmerischen Innovationsvorhaben: Psychologische Determinanten der Innovationsentscheidung, Working paper No. 40, Lehrstuhl für Allgemeine und Industrielle Betriebswirtschaftslehre, University of Munich.

Richins, M.L. (1994) 'Valuing things: the public and private meanings of possessions', Journal of Consumer Research, Vol. 21, No. 3, pp.504-521. 
Ryan, R.M. and Deci, E.L. (2000) 'Self-determination theory and the facilitation of intrinsic motivation, social development, and well-being', American Psychologist, Vol. 55, No. 1, pp.68-78.

Schreier, M. (2006) 'The value increment of mass-customized products: an empirical assessment', Journal of Consumer Behavior, Vol. 5, No. 4, pp.317-327.

Simonson, I. (2005) 'Determinants of customers' responses to customized offers: conceptual framework and research propositions', Journal of Marketing, Vol. 69, No. 1, pp.32-45.

Son, J., Sadachar, A., Manchiraju, S., Fiore, A.M. and Niehm, L. (2012) 'Consumer adoption of online collaborative co-design', Journal of Research in Interactive Marketing, Vol. 6, No. 3, pp.180-197.

Thaler, R. (1980) 'Toward a positive theory of consumer choice', Journal of Economic Behavior \& Organization, Vol. 1, No. 1, pp.39-60.

Thomke, S. and von Hippel, E. (2002) 'Customers as innovators: a new way to create value', Harvard Business Review, Vol. 80, No. 4, pp.51-61.

Ulrich, P.V., Anderson-Connell, L.J. and Wu, W. (2003) 'Consumer co-design of apparel for mass customization', Journal of Fashion Marketing and Management, Vol. 7, No. 4, pp.398-412.

von Hippel, E. (2005) Democratizing Innovation, MIT Press, Cambridge, MA.

Woodall, T. (2003) 'Conceptualising 'value for the customer': an attributional, structural and dispositional analysis', Academy of Marketing Science Review, No. 12, pp.1-41.

Zaichkowsky, J.L. (1985) 'Measuring the involvement construct', The Journal of Consumer Research, Vol. 12, No. 3, pp.341-352. 